\title{
Enabling T Cell Recruitment to Tumours as a Strategy for Improving Adoptive T Cell Therapy
}

\author{
Bruno Cadilha, Klara Dorman, Felicitas Rataj, Stefan Endres and Sebastian Kobold
}

Center for Integrated Protein Science Munich (CIPSM) and Division of Clinical Pharmacology, Department of Medicine IV, Klinikum der Universität München, Munich, Germany, Member of the German Center for Lung Research

l mmunotherapy has successfully been implemented as the standard of care in a number of oncologic indications. A hallmark of cancer immunotherapy is the successful activation of T cells against cancer cells, leading to unparalleled efficacy for some tumour entities. However, current approved approaches are not specific, limiting both their activity and their safety. A more tailored way of using the therapeutic potential of T cells is adoptive T cell therapy, which encompasses ex vivo T cell manipulation and reinfusion to patients suffering from cancer. In haematologic malignancies such as acute lymphatic leukaemia of the B cell lineage, T cells modified with a chimeric antigen receptor against the B cell lineage antigen CD19 induce remissions in a high proportion of patients. In contrast, patients suffering from advanced solid tumours have shown little benefit from cell-based approaches. This is partly due to limited access of T cells to the tumour tissue, consequently restricting T cell activity. In this review, we focus on the limitations of T cell trafficking towards solid tumours. We summarise the existing knowledge on lymphocyte migration to understand how this pathway may be used to open therapeutic approaches for a broader range of indications. We also review new strategies targeting the tumour site that aid naturally occurring or gene-engineered T cells to migrate to solid tumours. Finally, we discuss how guiding T cells towards the tumour might contribute in harnessing their full cytolytic potential.

\section{Keywords}

Adoptive T cell therapy, homing, immune supression, antigen recognition, CAR T cells, TCR T cells, TILS, chemokine receptors

Disclosure: Bruno Cadilha, Klara Dorman, Felicitas Rataj, Stefan Endres and Sebastian Kobold have nothing to declare in relation to this article. No funding was received in the publication of this article. This study involves a review of the literature and did not involve any studies with human or animal subjects performed by any of the authors.

Acknowledgements: This study was supported by grants from the Wilhelm Sander Stiftung (grant number 2014.018.1 to SE and SK), the international doctoral program 'i-Target: Immunotargeting of cancer' funded by the Elite Network of Bavaria (to SK and SE), the Melanoma Research Alliance (grant number N269626 to SE and 409510 to SK), the Marie-Sklodowska-Curie 'Training Network for the Immunotherapy of Cancer (IMMUTRAIN)' funded by the H2O2O program of the European Union (to SE and SK), the Else Kröner-Fresenius-Stiftung (to SK), the German Cancer Aid (to SK), the Ernst-Jung-Stiftung (to SK), by LMU Munich's Institutional Strategy LMUexcellent within the framework of the German Excellence Initiative (to SE and SK)

Authorship: All named authors meet the International Committee of Medical Journal Editors (ICMJE) criteria for authorship of this manuscript, take responsibility for the integrity of the work as a whole, and have given final approval to the version to be published.

open Access: This article is published under the Creative Commons Attribution Noncommercial License, which permits any noncommercial use, distribution, adaptation and reproduction provided the original author(s) and source are given appropriate credit.

Received: 24 February 2017

Accepted: 2 May 2017

Citation: European Oncology \& Haematology, 2017;13(1):66-73

Corresponding Author: Sebastian Kobold, Division of Clinical

Pharmacology, Klinikum der Universität München, Lindwurmstrasse 2a,

80337 Munich, Germany. E: sebastian.kobold@med.uni-muenchen.de
Cancer immunotherapy has come of age and has successfully been implemented as the standard of care in a number of oncologic indications. ${ }^{1}$ Antibodies targeting cancer-associated antigens on the tumour cell, such as CD20, constituted the first wave of immunotherapies leading to the first approval of an antibody for cancer therapy. In 1997, rituximab, an anti-CD20 antibody was approved for the treatment of high-grade B cell lymphomas.2 Twenty-one compounds with similar tumour-targeted concepts have been approved for cancer treatment in Europe in the meantime. Despite being thought that the mode of action of such antibodies mainly relied on a direct antitumoural attack, emerging evidence suggests a contribution of the innate and adaptive immune system. ${ }^{3-6}$ Tumour-targeted monoclonal antibodies are now mainly considered as a passive immunotherapy. ${ }^{7-10}$

More recently, a paradigm change has occurred, moving the focus of therapeutic endeavours away from the cancer cell to effector components of the immune system, mainly T cells. ${ }^{11}$ Preclinical and clinical evidence have now demonstrated that allowing $T$ cell activation results in antitumoural activity without bona fide tumour-targeting. Antibodies targeting checkpoint inhibitors on T cells such as, programmed death receptor 1 (PD-1) or cytotoxic T-lymphocyte-associated antigen 4 (CTLA-4), reverse $T$ cell anergy and lead to $T$ cell-mediated remissions. Such antibodies can induce unparalleled activity in patients with advanced stage disease or having failed multiple lines of therapy, even in entities classically deemed nonsuitable for immunotherapies. As a consequence, approvals for cancer immunotherapies now span a broad scope of indications including acute lymphatic leukaemia (ALL), melanoma, nonsmall cell lung cancer, kidney cancer, Hodgkin lymphoma and head and neck cancer. ${ }^{12-17} \mathrm{~A}$ major limitation of the approach is its unspecific nature of $\mathrm{T}$ cell targeting, resulting in severe side effects. ${ }^{18-20}$ Strategies allowing for a more directed and specific therapeutic use of T cells may have advantages in terms of specificity and efficacy. 
Figure 1: Modalities of adoptive T cell therapy

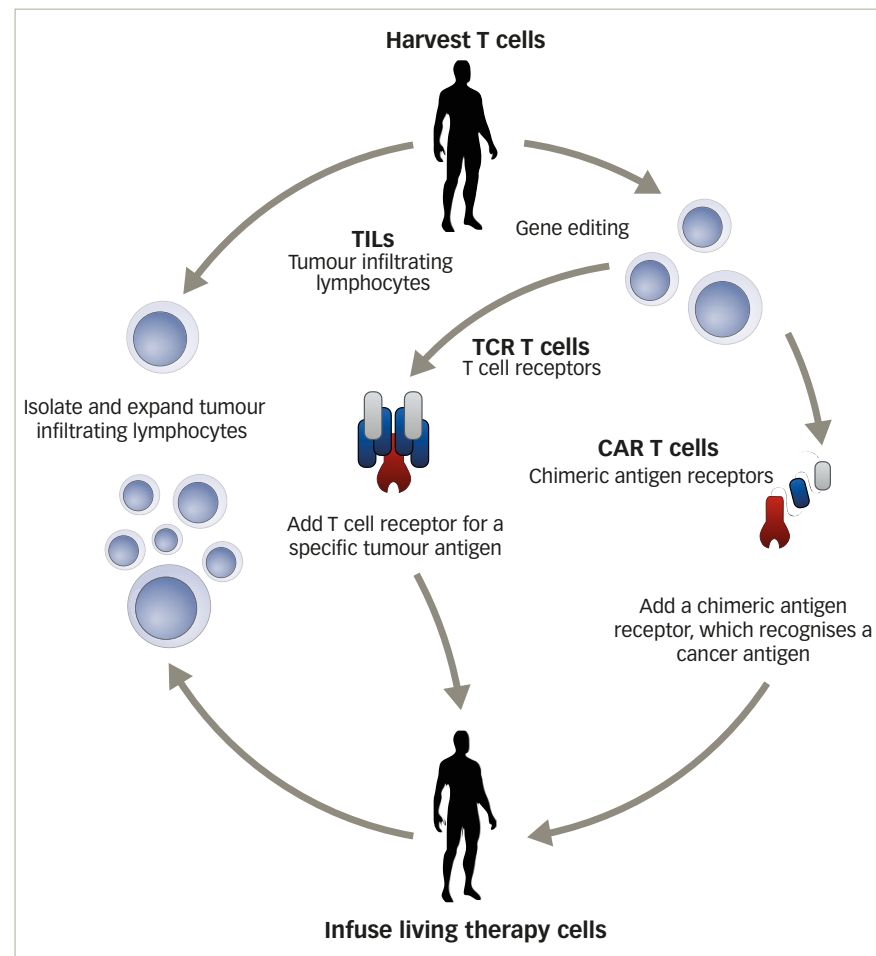

$T$ cell therapy modalities can be divided into three different approaches. On the one hand, tumour infiltrating lymphocytes are naturally occurring T cells isolated from cancer patients. On the other hand, genetically modifying approaches can be divided either into tumour-specific T cell receptor or chimeric antigen receptor transduced $T$ cells. CAR = chimeric antigen receptor; $T C R=T$ cell receptor; TILS = tumour infiltrating lymphocytes.

Adoptive T cell therapy (ACT) is a strategy that directly employs T cells with therapeutic intention against cancer. ${ }^{21} \mathrm{~T}$ cells can be isolated from a patient's blood or tumour samples. Those derived from the tumour are also known as tumour-infiltrating lymphocytes (TILS). ${ }^{21,22}$ Isolation is followed by in vitro expansion and manipulation, and then reinfusion into the patient. ${ }^{21}$ ACT protocols that employ TILs are generally accompanied by preconditioning of the patients prior to treatment. In most cases, however, TILS cannot be isolated due to the lack of accessible tumour tissue or lack of tumour-specific T cells. ${ }^{23}$ Through genetic engineering, $\mathrm{T}$ cells can be rendered specific for a given target. This process encompasses the transduction or transient transfection with defined natural or synthetic genes. Two major strategies to engineer tumourspecific T cells have emerged: T cell receptors (TCRS) ${ }^{24-26}$ specific for a peptide presented in a major histocompatibility complex-dependent manner, and chimeric antigen receptors (CARS) $)^{27-30}$ which are synthetic $T$ cell activating receptors targeting cell surface antigens. TCRs correspond to the natural molecule found in any $T$ cell with modifications to enhance their biochemical and functional properties, while CARs are constituted of the variable fragment of an antibody fused to T cell activating CD3 zeta chain and co-stimulatory domains (overview in Figure 1). TILS, TCR and CAR T cells are currently being tested in various tumour indications in clinical trials (Figure 2).

\section{Clinical efficacy of adoptive T cell therapy}

ACT has so far been successfully applied in patients suffering from melanoma, myeloma, cervical cancer, lymphoma, bile duct cancer, neuroblastoma and others. ${ }^{21,31,32}$ For TIL-based therapies, highest clinical benefit has been observed in melanoma in conjunction with total body irradiation or nonmyeloablative chemotherapy as preconditioning regimens. In a study where 93 patients with metastatic melanoma
Figure 2: Overview of the clinical trials landscape on TILS, TCR T cell and CAR T cell-based therapies

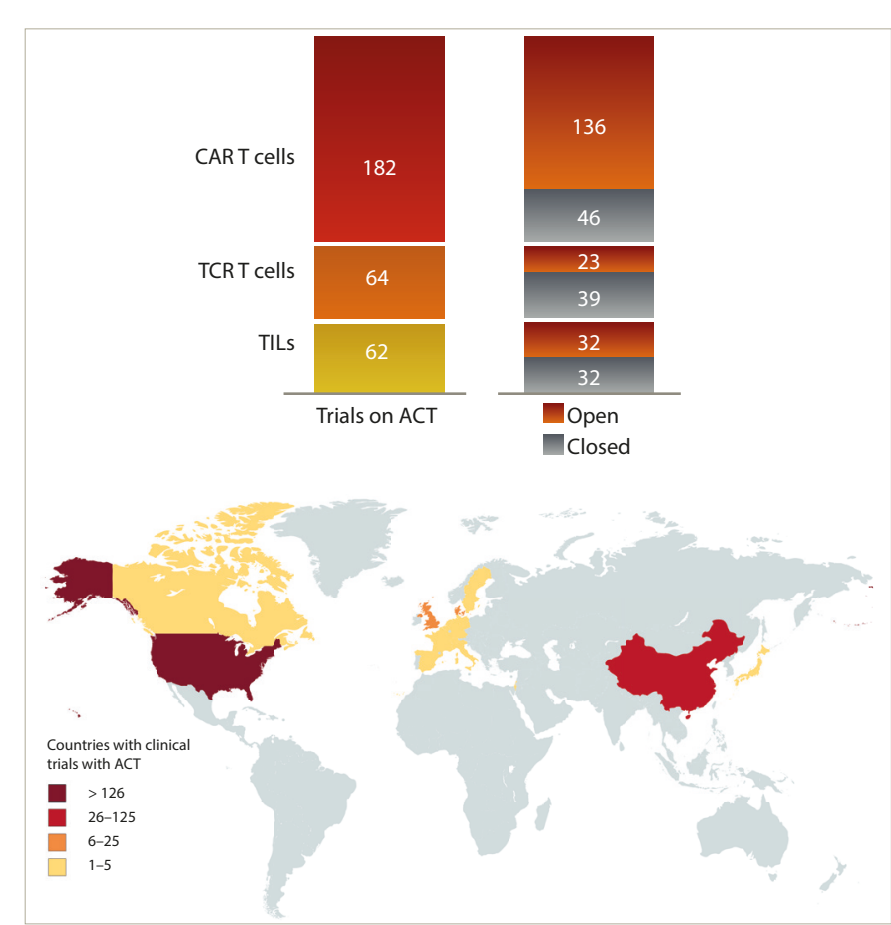

The numbers were retrieved from www. clinicaltrials. gov by searching for the key terms ' $T I L$ ', 'TCR' and 'CAR'. A total of 913 studies met this requirement and were further selected if they had an interventional arm using either TILS, TCR or CAR T cells alone or in combination, narrowing the results down to 308 studies. ACT = adoptive $T$ cell therapy; $C A R=$ chimeric antigen receptor; $T C R=T$ cell receptor; $T I L S=$ tumour infiltrating lymphocytes.

were treated with autologous TILS administered in conjunction with interleukin (IL)-2 following a lymphodepleting regimen, 20 patients achieved a complete and mostly lasting tumour regression. These 20 complete responders had 3 - and 5 -year survival rates of $100 \%$ and $93 \% .^{33}$ The antitumour effects of melanoma-derived TILs have encouraged trials in other indications with limited success. TILs have been extensively characterised through whole-exome sequencing and other approaches. A surprising feature was that few T cells of the TIL product were in fact tumour-specific or at least of definable specificity. ${ }^{34-36}$ The high response rates of patients with advanced melanoma to TIL therapy have prompted the initiation of a phase III clinical trial comparing TIL therapy to ipilimumab treatment as standard of care arm (NCT02278887).

TCR-modified T cells have so far mainly been used in phase I or ॥ clinical trials. Early attempts using melanoma-associated antigen 3 (MAGE-A3)-specific $T$ cells reported objective responses in five out of nine treated patients. However, at the same time, two patients died due to neurotoxicity, probably related to expression of a closely related antigen on the brain, highlighting the risks associated with high-affinity TCRs. ${ }^{37}$ Similarly, in another study two patients developed a cardiogenic shock and died within days of $T$ cell therapy infusion with the autopsy showing myocardial $T$ cell infiltration. No expression of MAGE-A3 on heart tissue was found but the TCR was then demonstrated to cross react with an epitope of another antigen, namely titin. This further stresses the potential difficulties of predicting off-target effects of such a potent therapy. ${ }^{38}$ Objective responses have also been reported using TCRs specific for MAGE-A4 in oesophageal cancer, for MART-1 in melanoma, for NY-ESO-1 in melanoma, myeloma and synovial sarcoma, as well as for carcinoembryonic antigen (CEA) in colon cancer. ${ }^{39-43}$ The most prominent responses have so far been seen in patients with melanoma 


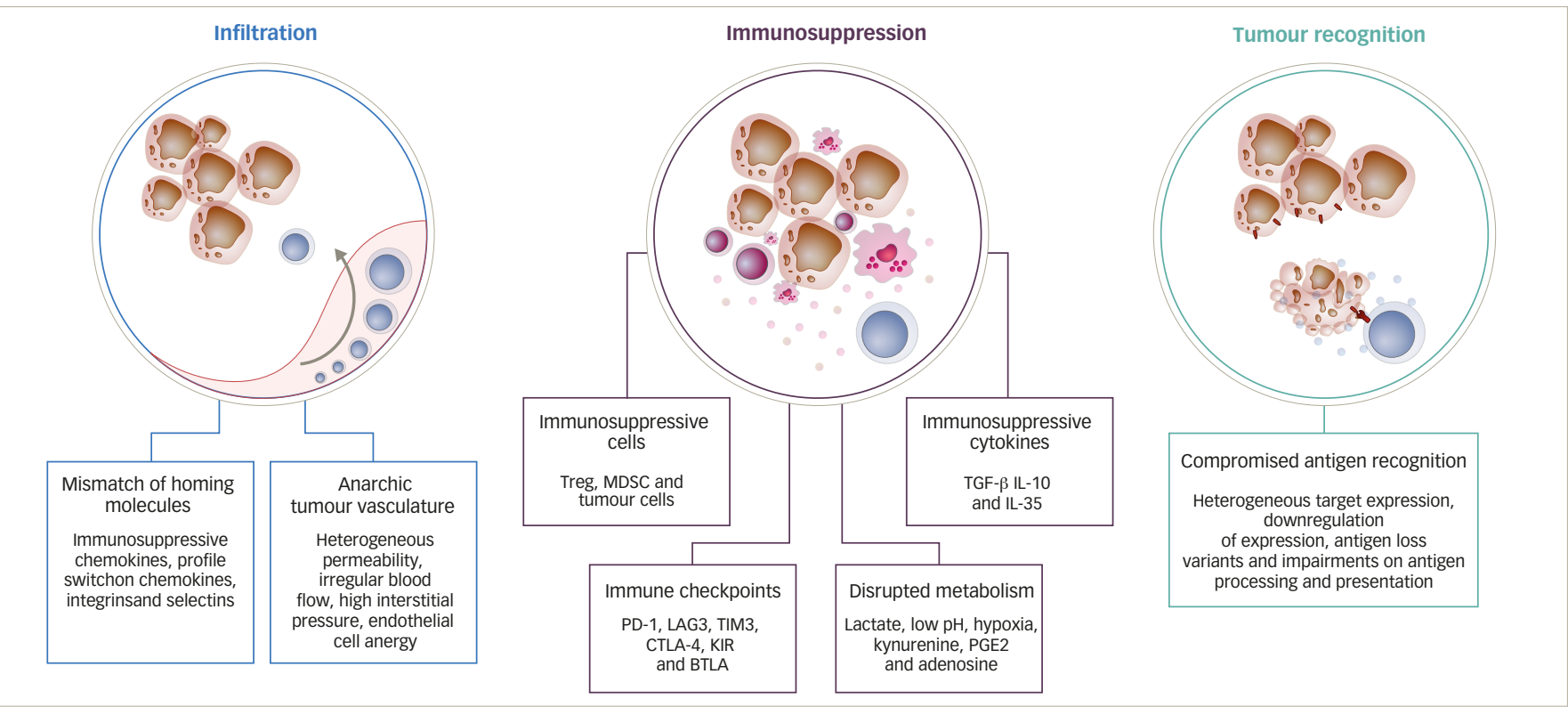

Adoptive T cell therapy faces three major limitations. Infiltration is impaired through chemokine receptor-ligand mismatches and anarchic tumour vasculature. Immunosuppression can be exerted through cell bound or soluble factors and metabolic changes that can also be cell based or in the form of soluble products derived from disrupted metabolisms. Finally, despite advances on the field, antigen recognition is still an unsolved issue, giving rise to tumour escape variants resistant to available therapies. $B T L A=B$ - and T-lymphocyte attenuator; CTLA = cytotoxic T-lymphocyte-associated protein 4; IL = interleukin; KIR = killer cell immunoglobulin-like receptor; $M D S C=$ myeloidderived suppressor cells; PD-1 = programmed death 1; TGF = transforming growth factor; TIM3 = T-cell immunoglobulin domain and mucin domain 3; Treg = regulatory T cell.

treated with NY-ESO-1-TCR-transduced T cells. The treatment regimen included IL-2 and preparative chemotherapy. ${ }^{40}$

CAR-transduced T cells have been mainly tested in patients suffering from haematologic malignancies. The most used target is CD19, a B cell lineage antigen, expressed in a wide variety of entities such as B cell lymphomas and B cell leukaemias. Several clinical CD19-CAR candidates developed by different groups are currently under investigation with similar but not identical structures nor sequences. In adult and paediatric ALL, CD19-CAR T cells have induced major clinical responses with complete remission rates as high as $90 \%$ (27 out of 30 patients). ${ }^{44}$ Similar results could be confirmed in independent trials using distinct CD19-CAR constructs. ${ }^{45}$ Data from other B cell malignancies could confirm CAR T cell activity but seem to indicate a trend towards enhanced response rates in more aggressive haematologic malignancies. For example, response rates for patients with diffuse large B cell lymphoma were four complete remissions out of seven patients treated (57\%), as opposed to four out of 14 patients (29\%) with chronic lymphatic leukaemia in another study. ${ }^{46}$ In contrast, efficacy of CAR targeting nonhaematologic malignancies and using different targets have proven significantly less successful with so far only little objective responses observed in clinical trials. CAR therapy has proven to have a manageable safety profile in these small cohorts and in specialised centres. However, several neurotoxicityassociated deaths have recently occurred in a single ongoing CD19CAR T cell trial with a defined CAR which were not observed in other parallel trials (NCT01044069, NCT01840566, NCT02535364). ${ }^{47-49}$ Earlier, an ERBB2-recognising CAR induced a severe cytokine storm syndrome that led to death of one patient within 5 days of therapy. The authors postulated that the severe cytokine storm was induced by on-target offtumour recognition upon first-pass clearance in the lung. This cytokine storm caused pulmonary toxicity and oedema, resulting in multiorgan failure..$^{50}$ While the first approval of a CAR therapy seems to be in sight, the toxicity together with the limited efficacy in solid tumours call for a better understanding of the underlying mechanisms of action as well as strategies to overcome their inherent limitations.

\section{Limitations to adoptive T cell therapy efficacy}

Safety of application is the major limitation to ACT and has been extensively reviewed recently..$^{51}$ After the T cells have been administered to the patient, three major mechanisms limit their antitumoural potency and efficacy (Figure 3):

\section{- limited access to the tumour tissue; \\ - limited recognition and lysis of tumour cells; and \\ - local immune suppression.}

The process of distribution of T cells to the tumour site and subsequent activity is complex, requiring migration, persistence, and activation of the $T$ cell in a given tissue. ${ }^{28}$ As $T$ cells are natural antitumoural effectors, strongly involved in the editing and elimination phases of cancer development, tumours have mounted complex strategies to selectively exclude $T$ cells from their vicinity. ${ }^{52}$ Mechanisms include pathologic vascularisation limiting $T$ cell influx and extravasation, ${ }^{53}$ selective expression or repression of integrins, or production of chemokines excluding $T$ cell attraction. ${ }^{54-58}$ Along these lines, even $T$ cells that have managed to enter tumour tissue are limited in their activity due to a lack of tumour recognition. The latter being due to heterogeneous target expression, downregulation of expression, antigen loss variants (as a result of either self-mimicry or tolerance) or impairments on antigen processing and presentation. 59,60 On the other hand, even in the case of effective tumour recognition, tumour cells are still able to repress T cell activation. Tumours can suppress T cell function through soluble or cell bound factors, as well as the induction and attraction of suppressive cell populations. This local immune suppression, which may also escalate to become systemic, includes factors such as transforming growth factor beta (TGF- $\beta$ ), indoleamine 2,3-dioxygenase (IDO), PD-1-PD-L1 interactions, myeloidderived suppressor cells or regulatory T cells..$^{6,56,61}$

A major focus of development over the past years has been on the enhancement of tumour recognition through discovery of new target 
epitopes for $\mathrm{CARS}^{62}$ (listed on the Cancer Immunity Peptide Database ${ }^{63}$ ) and additional engineering of these receptors with series of modifications on co-stimulatory molecules, ${ }^{64,65}$ hinge regions ${ }^{66}$ and transmembrane regions. ${ }^{67-73}$ However, the clinical value of these modifications is unclear, as comparative clinical studies have yet to be pursued. As T cells used in ACT are, in general, as sensitive to suppression as endogenous cells, a growing body of evidence points towards the combination of ACT with immune-activating strategies. Preclinical evidence indicates that combination of ACT with immune checkpoint blockade will overcome immune suppression and lead to synergistic activity. ${ }^{74}$ Several clinical trials have been launched to test the combination of TCR, CAR or TIL ACT with checkpoint blockade (NCT02652455, NCT03030001, NCT02873390, NCT02862028, NCT02858310, NCT02775292, NCT02070406). Solid tumours have been recognised as entities that do not respond significantly to CAR ACT. Comprehensive overviews of clinical ACT experience in solid tumours have been recently published. Johnson and June have reviewed current ACT clinical trials on solid tumours and compared TCR to CAR T cell trials, ${ }^{75}$ and Yong and colleagues have circled the limitations of ACT in solid tumours. ${ }^{76}$

While the main efforts in the past years to improve ACT have been put on tumour recognition and immune suppression, less emphasis has been put on the prerequisite for either mode of action: the access of $\mathrm{T}$ cells to the tumour tissue. Here we will summarise available evidence to tackle this central issue.

\section{T cell migration and entry into tumours}

In cancer immunotherapy, T cell trafficking has recently come into spotlight due to the findings that higher TILs correlate with better clinical outcomes. ${ }^{77}$ This is particularly evident for gliomas, ${ }^{78}$ colorectal, ${ }^{79}$ breast ${ }^{80}$ and cervical cancers. ${ }^{81}$ An international consortium is currently prospectively validating this prognostic parameter as an 'immunoscore' for colorectal cancer. Such a score may, in the near future, be used in clinical routine. ${ }^{82}$ This body of evidence has confirmed the preclinical observations that high $T$ cell infiltrations are required for adequate antitumoural activity of $T$ cells. To gain access to tumours or to any tissue, T cells need to pass through the two-step process of leukocyteendothelial cell interaction proposed by von Andrian and colleagues. ${ }^{83,84}$ This model postulates that selectins play a crucial role on the first adhesion of leukocytes to the endothelial walls. In a rather weak manner, this selectin binding allows cells to slow down and form more stable bridges though second mediators, integrins, that will subsequently be responsible for the trafficking of leukocytes. ${ }^{83}$ The multistep adhesion cascade, comprises three key steps of rolling, adhesion, and migration requiring $\mathrm{G}$ protein-coupled receptors for the activation of the integrin signal on T cells..$^{85-89}$ These particular G protein-coupled receptors are also referred to as chemokine receptors and control migration. ${ }^{90-94}$ Chemokine receptors include four conserved cysteine residues in their sequences, which form different patterns of disulphide bonds. The spacing of two relevant cysteines defines five families: the CC-, CXC-, XC-, CX3C- and $\mathrm{CX}$ - family of chemokines. An $\mathrm{L}$ is added to identify ligands, and within families different proteins are distinguished with numbers. ${ }^{95,96}$

The key signalling event triggered intracellularly after the binding of chemokine ligand to its cognate receptor is a cytosolic calcium elevation (Figure 4). The change of conformation in the chemokine receptor allows activation of the $\mathrm{G}$ protein that, in turn, will activate phospholipase $\mathrm{C}$. This cleaves phosphatidylinositol diphosphate into diacylglycerol, that activates protein kinase $\mathrm{C}$, and into inositol triphosphate which triggers calcium elevation. This chain reaction wind up in signalling via MAPK, ERK and JAK, which induce the expression of other proteins promoting cell migration. ${ }^{97-99}$
Figure 4: Key events of chemokine receptor-ligand cascade

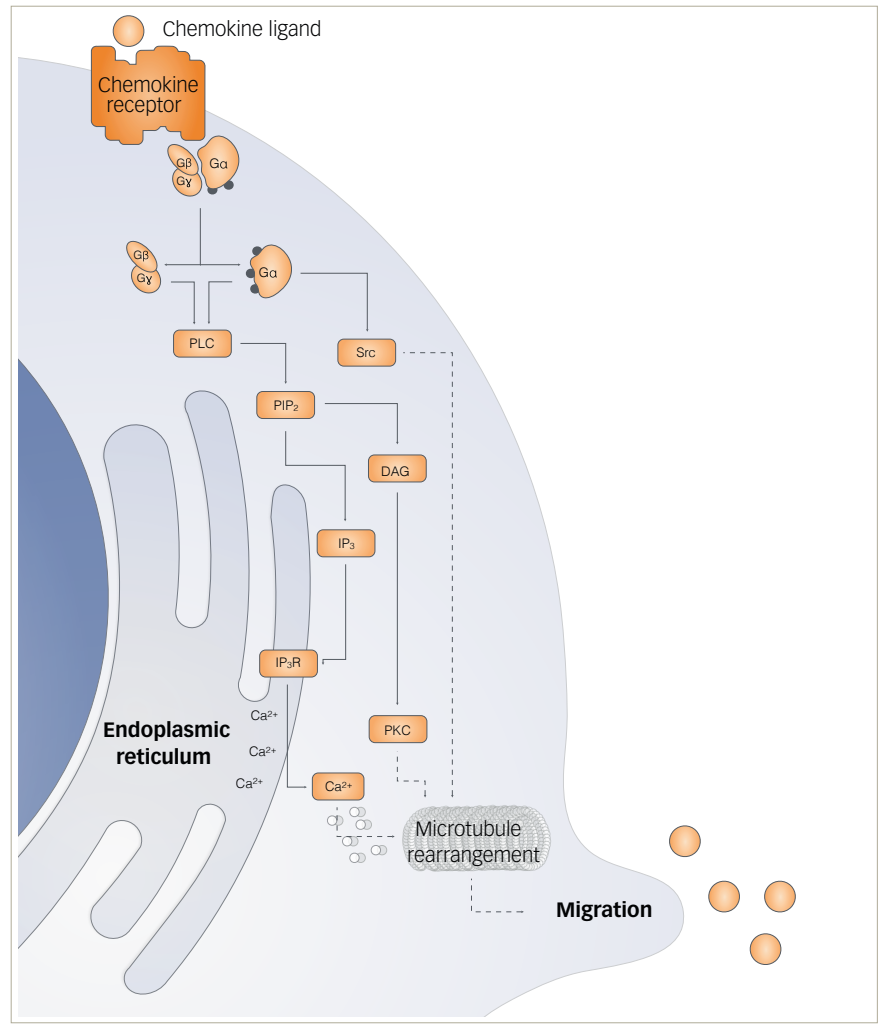

Chemokine ligand binding to its corresponding chemokine receptor will trigger the uncoupling of different subunits of its coupled $G$ proteins. The $\alpha$ subunit of the $G$ proteins can either be a Gaq or a Gai. Most chemokine receptors rely on Gai, but they may as well signal through Gaq. Ga subunits will mainly signal through Src pathway activation to lead to regulation of actin cytoskeleton and active migration. The $\beta$ and $\gamma$ subunits of the $G$ proteins on the other hand rely more on the activation of phospholipase C. PLC hydrolyses phosphatidylinositol 4,5-bisphosphate to generate the secondary messengers inositol 1,4,5-triphosphate and diacylg/ycerol. IP3 will lead to the activation of the inositol triphosphate receptor generating a calcium efflux from the endoplasmic reticulum (ER) towards the cytoplasm and DAG will activate protein kinase $C$. These events culminate in microtubule rearrangement and localisation of more chemokine receptors in filopodia that rise towards the chemokine ligand gradient. $D A G=$ diacylglycerol; $E R=$ endoplasmic reticulum; IP3 = inositol 1,4,5-triphosphate; IP3R = inositol triphosphate receptor; PIP2 = phosphatidylinositol 4,5-bisphosphate; $P K C=$ protein kinase $C ; P L C=$ phospholipase $C$

\section{Tumours shape their chemokine milieu by excluding T cells, recruiting suppressive cell populations, triggering metastasis and disrupting vasculature anatomy}

Cells of different tumour entities will express different patterns of chemokines such as CCL2 to CCL5, CCL8, CCL9, CCL17, CCL19, CCL21, CCL22, CCL26 to CCL28, CXCL1 to CXCL8 and CXCL12 to shape their tumour microenvironment. ${ }^{100,101}$ By altering the levels of key chemokines, some tumours are able to avert immunologic surveillance of tissue resident lymphocytes. For example, certain types of ovarian and breast cancers have been proven to upregulate CCL22 and CCL28, ${ }^{102,103}$ which are central chemokines for the recruitment of regulatory T cells. ${ }^{104}$ In colorectal tumours there is upregulation of CCL2, a chemokine central for the recruitment of tumour-associated macrophages and T cells. ${ }^{105}$ Melanomas show an even broader response by decreasing expression patterns of CCL2, CCL3, CCL4, CCL5, CXCL9 and CXCL10 $55,{ }^{106}$ which control the recruitment of not only $\mathrm{T}$ cells, but also of proinflammatory immune cells, thereby contributing to immune evasion. As further evidence that the modulation of chemokine patterns might be used by tumours to control the trafficking of T cells the induction of specific chemokine ligands in melanoma triggers the recruitment of T cells to the tumour site. ${ }^{55}$ Tumour-derived microvesicles have been shown to induce secretion of CXCL8, CCL2, CCL3, CCL4 and CCL5. ${ }^{107}$ 
Figure 5: Transfer of CCR4-transduced OT-1 (T) cells induces regression of established tumours

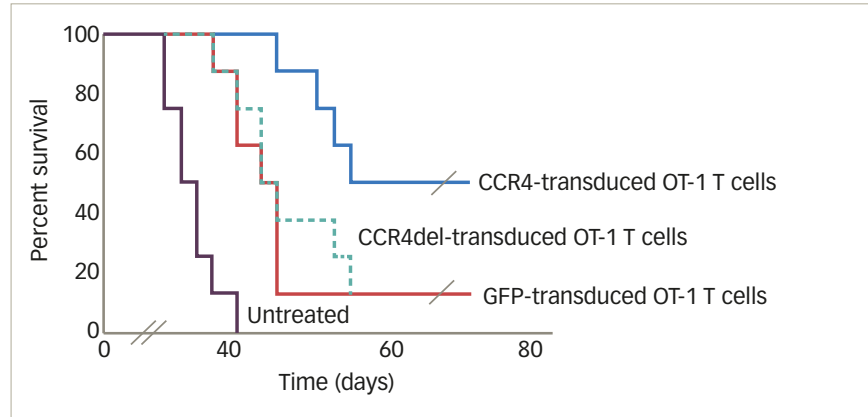

Mice bearing established subcutaneous Panc02-OVA tumours were IV injected 6 and 12 days after tumour induction with $2 \times 106$ OT-1 T cells transduced with GFP, CCR4 or CCR4del and tumour growth and survival was monitored every second day. (Reproduced under the Creative Commons Attribution-Non-Commercial License from Rapp et al., 2016) $)^{104}$

CCL2, CCL5, CXCL5 and CXCL12, have been shown to promote tumour progression by increasing the formation, recruitment and suppressive activity of tumour-associated macrophages and myeloid-derived suppressor cells. ${ }^{108-110}$

Besides shaping their environment to reduce the number of infiltrating effector $\mathrm{T}$ cells, tumours may also take advantage of chemokine receptors to initiate metastasis. CCL5 has been found to be produced in prostate cancers and osteosarcomas improving the survival of tumour cells through increased angiogenesis. ${ }^{111}$ Myeloid cells that produce metalloproteinases 2 and 9 have been found to migrate towards CCL9 in colon cancer models potentially improving invasive growth of tumours. ${ }^{112}$ CXCR4 expression on tumour cells, on the other hand, is associated with metastasis from prostate cancer, lung cancer and glioblastoma even though this receptor is not expressed physiologically in all of these tissues. ${ }^{113}$ The axis CCL1CCR8 is believed to play a role in initial stages of metastasis from the primary tumour site to the subcapsular sinus of lymph nodes. ${ }^{114}$ Several of the chemokines previously mentioned also have angiogenic properties: pro-angiogenic properties have been ascribed to CXCL1, CXCL2, CXCL3, CXCL5, CXCL6, CXCL7, CXCL8 and CXCL12, whereas anti-angiogenic properties have been associated to CXCL9, CXCL10, CXCL11 and CXCL14. ${ }^{115}$ Disruption of these pathways will result in defective or anarchic tumour vasculature that will hamper migration of the immune effector cell to the tumour site. ${ }^{116,117}$ In summary, available data strongly suggests that chemokines are key players in cancer progression by several mechanisms. As a consequence, therapeutic strategies modulating this axis may restore immune surveillance and T cell efficacy.

\section{Modulation of the local chemokine milieu to recruit $T$ cells to the tumour}

Therapeutic approaches have shown the potential of modulating the tumoural chemokine milieu to either improve the trafficking of effector cells or to decrease the trafficking of immunosuppressive cells towards the tumour. Small molecules blocking CCR4 decrease the amount of T regulatory cells in tumours, antagonising CCL17- or CCL22-mediated Treg-recruitment to the tumour. ${ }^{118-120}$ In vitro, some truncated chemokines can act as antagonists to their cognate receptors such as CXCL8, CCL5 and CCL2. ${ }^{121-123}$ Several antibodies targeting chemokine ligands are being tested for tumour immunotherapy. However, only a truncated analogue of CCL2 has shown efficiency in decreasing the recruitment of tumour-associated macrophages. ${ }^{124,25}$ An antibody targeting CCR4, mogamulizumab, is approved in Japan for the treatment of $\mathrm{T}$ cell Iymphoma. ${ }^{26}$ Other antibodies targeting different chemokines and chemokine receptors for tumour immunotherapy have been developed and are currently in clinical trials. ${ }^{125}$

Chemokines and chemokine receptors in the tumour tissue may also be induced in the course of therapy: treatment of tumour-bearing mice with chemotherapy (dacarbazine, temozolomide and cisplatin) induced intratumoural expression of CXCR3 and CCL5, enabling T cell infiltration into cutaneous tumours. ${ }^{106}$ PD-1 pathway blockade has been reported to increase IFN- $\gamma$ at the tumour site, thereby increasing chemokinedependent trafficking of immune cells into malignant disease sites. ${ }^{127}$ Heparins can inhibit interferon gamma (IFN- $\gamma$ )-induced chemokines, namely CXCL9 and CXCL10 and lead to recruitment of pro-inflammatory immune cells. ${ }^{128}$ CCL1 blockade has proved in murine models to reduce intratumoural accumulation of $\mathrm{T}$ regulatory cells decreasing the immunosuppression in the tumour and allowing more effective T cell function. ${ }^{129}$ In ovarian cancer models, the infusion of NKG2D-CARexpressing $T$ cells increased the number of host CD4+ and CD8+ T cells at the tumour site in a CXCR3-dependent manner and increased the number of antigen-specific host CD4+ T cells in the tumour and draining lymph nodes. This showed that adoptively transferred $T$ cells recruit and activate endogenous $T$ cells. This contributes to the elimination of tumour cells and to the development of tumour-specific memory responses. ${ }^{130}$ Other forms of immunotherapy also have the capacity of changing the chemokine receptor-ligand pattern in tumours such as Listeria monocytogenes-based anticancer vaccine ${ }^{131}$ or even systemic IL-12 treatment. ${ }^{132}$ It is surprising that, to date, no clinical trial has yet been initiated to investigate therapeutic interference with the chemokine pattern in combination with ACT, aside from - indirectly - when administering checkpoint blockade.

\section{T cell engineering with chemokine receptors for enhanced tumour-directed migration}

Upon development in primary lymphoid structures, T cells only obtain a limited amount of information about self and nonself antigens. They have not completed their specificity maturation until they encounter antigen-presenting cells at secondary lymphoid structures. ${ }^{88}$ This step is known as priming ${ }^{133}$ and it allows T cells to tune their activity against a specific antigen and to expand their cytolytic potential. ${ }^{334-137}$ Another function of the encounter of the antigen-presenting cell with the T cell is to regulate their subsequent homing through molecular migration signatures for selected tissues. ${ }^{138-143}$ As a consequence, T cells will only express a limited repertoire of chemokine receptors naturally. Therapeutic transduction of $\mathrm{T}$ cells with defined chemokine receptors and thus modulation of their migration signatures may enhance efficacy of ACT.

Kershaw and colleagues were the first in 2002 to arm T cells with chemokine receptors to make use of CXCL1 overexpression in tumours by tumour cells. As the corresponding receptor, CXCR2, was not found on T cells, the authors retrovirally transduced T cells to overexpress this receptor. ${ }^{144}$ In murine tumour models they demonstrated the feasibility of changing the chemokine receptor profile of $\mathrm{T}$ cells towards chemokines secreted by tumours. The value of CXCR2 as a chemokine receptor of choice was later confirmed by using an approach of mRNA transfection, potentially offering superior safety. ${ }^{145}$

The combination of CAR T cell therapy and chemokine receptors has repeatedly proven to be synergistic or at least additive in terms of activity in preclinical trials. Co-expression of CCR4 on CAR-CD30-modified T cells improved homing to $\mathrm{CD} 30+$ Hodgkin lymphoma, consequently improving the effectiveness of $\mathrm{ACT}^{146}$ In a neuroblastoma model, expression of 
CCR2b redirected GD2-CAR-transduced T cells generating greater anti-tumour activity. ${ }^{177}$ High secretion of CCL2 by malignant pleural mesotheliomas allowed for the use of this chemokine gradient to recruit gene-modified T cells transduced with CCR2. These cells also carried a CAR construct that conferred them antigen specificity for mesothelin. CAR T cells that bore a functional chemokine receptor were able to overcome the inadequate tumour localisation that limits conventional CAR targeting strategies and can significantly improve antitumour efficacy in vivo. ${ }^{148}$ Our group has shown that CCR4 transduction enhances the migration of $\mathrm{T}$ cells to the tumour microenvironment in a pancreatic tumour model (Figure 5). The cytolytic activity of engineered T cells was increased, stressing the importance of considering not only tumour cells as targets, but also other immune infiltrating cells. ${ }^{104}$

Engineering through CX3CR1 improved tumour growth control with higher infiltration rates of CX3CR1-engineered T cells in a gradient-dependent manner in human colorectal cancer models in immunodeficient mice. ${ }^{149}$

Natural killer (NK) cells have also been of interest for migration modulation through chemokine receptors. CCR7 increased the efficacy of NK cells that had further been engineered with the high-affinity antibody-binding receptor CD16, against rituximab-coated lymphoma cells. ${ }^{150} \mathrm{Xu}$ and colleagues have engineered a photoactivatable-CXCR4 that reacts by directing the migration of cell towards $505 \mathrm{~nm}$ light. ${ }^{151}$

Despite the success so far, there is a limited number of current clinical trials with chemokine receptor-transduced T cells. The MD Anderson Cancer Center is currently running a clinical trial with TILs transduced with CXCR2 (NCT01740557). The goal of this clinical trial is to assess the side effects of CXCR2-transduced TILs in combination with chemotherapy (cyclophosphamide and fludarabine) and aldesleukin, in patients with metastatic melanoma, in an attempt to allow them to better localise the tumour. The study has the toxicity of CXCR2-transduced TILS as its current primary outcome and tumour response using Immune-Related Response Criteria as a secondary outcome. Only one control arm has been set for this study, with each patient receiving a therapy consisting of both CXCR2-transduced TILs and nerve growth factor receptor (NGFR)transduced TILs (control cells).

\section{Modulation of T cell trafficking beyond chemokine - chemokine receptor interactions}

The possibilities for controlling $T$ cell trafficking and redirecting them to the tumour are broader than the direct or indirect modulation of chemokine ligands and receptors (Figure 6). Different chemotherapies given in low doses also have the potential, besides the previously mentioned capacity of modulating the chemokine milieu, to selectively decrease immunosuppressive cells and induce an anti-angiogenic activity. ${ }^{152}$ The combination of doxorubicin and IL-12 improved the trafficking of NKG2D T cells towards the breast tumours. ${ }^{153}$

Delivery of IL-12 into murine tumours using T cells genetically engineered to express an anti-vascular endothelial growth factor receptor (VEGFR)-2 CAR lead to tumour regressions without the need for IL-2 regimens. Anti-VEGFR-2 CAR and IL-12-co-transduced T cells infiltrated tumours, expanded, and persisted for prolonged periods. ${ }^{154}$ VEGF expression in tumours correlates with poor levels of infiltrating $T$ cells, ${ }^{155}$ and, vice versa, bevacizumab, an anti-angiogenic antibody improved $\mathrm{T}$ cell infiltration into solid tumours. ${ }^{156}$ Other antiangiogenic drugs, namely anginex, endostatin and angiostatin enhanced $\mathrm{T}$ cell infiltration in murine colon cancer and melanoma models. ${ }^{155,157}$
Figure 6: Strategies to improve T cell infiltration of the tumour

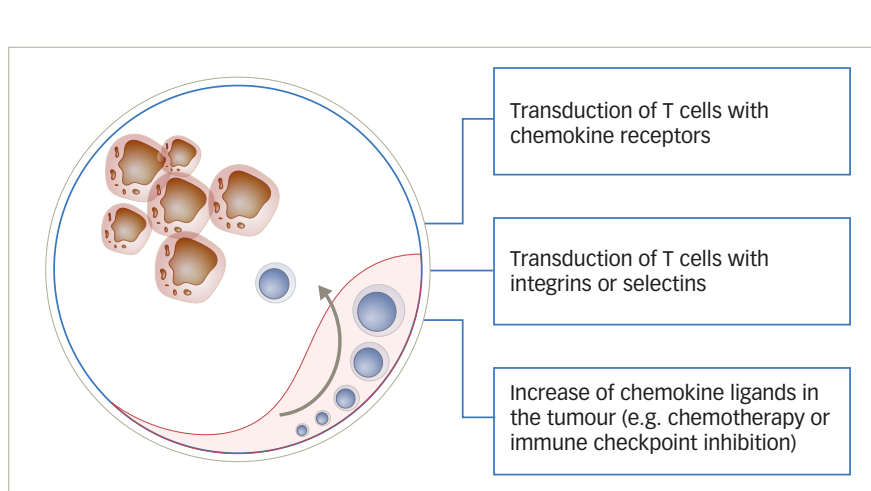

All adoptive $T$ cell therapies destined to treat solid tumours may benefit from combination with strategies to redirect trafficking to the tumour site. These include chemokine receptor engineering of the T cells, as well as modulations of the chemokine patterns on the tumour and its microenvironment. Besides these, proteins such as integrins and selectins also have the potential to improve redirection of $T$ cells. chemotherapy and immune checkpoint blockade can also improve $T$ cell trafficking. Finally, bispecific antibodies have the potential to increase cell to cell interaction improving the anchoring of $T$ cells to tumour cells.

Radiation also alters tumour vasculature and can improve the access of T cells to tumours. ${ }^{158}$ On another line, the disruption of tumour function of endothelin B receptor can facilitate the access of $T$ cells through the endothelial barrier. ${ }^{159}$ Improving homing through integrins has proved successful in preclinical models with $\mathrm{T}$ cells engineered with integrin alpha $v$ beta 3 showing benefits in vascularised solid tumours. ${ }^{160}$ Immune checkpoint blockade, besides directly allowing the intratumour activation and expansion of $\mathrm{T}$ cells, also increases production of IFN- $\gamma$-induced cytokines and chemokines. This leads to the recruitment of more effector cells to the tumour site. ${ }^{161}$ Our own group showed, that in a murine gastric cancer model, a bispecific antibody targeting on the one hand EGFRtransduced T cells, and on the other hand EPCAM bearing tumour cells increases recruitment of these engineered T cells to the tumour site. ${ }^{162}$ Bispecific antibodies targeting tumour cell and $T$ cell simultaneously are tested in clinical trials on patients whose tumours express different antigens such as EPCAM, HER2, CEA and PSMA (NCT00635596, NCT01284231, NCT01723475, NCT00351858).

Finally, in rare cases, the issue of migration into the tumour after systemic administration of $\mathrm{T}$ cells may be overcome through local administration of CAR T cells. ${ }^{163}$ This results in higher accumulation at tumour sites and superior control of tumour growth. ${ }^{164}$ This strategy is, however, only envisionable when the tumour site is readily accessible. This is the case, for example, for malignant pleural mesothelioma where the pleural space is directly accessible through a minimally invasive puncture.

\section{Conclusion and outlook}

TIL, TCR-transduced T cell and CAR-transduced T cell therapies are under clinical investigation for cancer treatment. Current clinical trials will decide on their approval for certain indications. While some of these strategies are likely to be approved in defined indications such as ALL, the majority of tumour patients will not benefit from this approach in the near future. A major reason, especially for solid tumours, is the limited access of adoptively administered T cells to the tumour tissue. Strategies such as $\mathrm{T}$ cell engineering with chemokine receptors need to be tested in clinical protocols based on preclinical evidence. However, it needs to be stressed, that those cells that eventually reach the tumour, still need to recognise the tumour cell adequately and prevail over immunosuppression. This will require both advanced T cell engineering and combination with other immune and nonimmune therapies. $\square$ 
Kobold S, Duewell P, Schnurr M, et al., Immunotherapy in tumors, Dtsch Arztebl Int, 2015;112:809-15.

2. Dotan E, Aggarwal C, Smith MR, Impact of rituximab (rituxan) on the treatment of B-cell non-Hodgkin's lymphoma, $P T_{\text {s }}$ 2010;353:148-57.

3. Smith MR, Rituximab (monoclonal anti-CD20 antibody): Mechanisms of action and resistance, Oncogene 2003:22:7359-68.

4. Boross P, Leusen JHW, Mechanisms of action of CD2O antibodies, Am J Cancer Res, 2012;2:676-90.

5. Scott AM, Wolchok JD, Old $\sqcup$, Antibody therapy of cancer, Nat Rev Cancer, 2012;12:278-87.

6. Tumeh PC, Harview $C L$, Yearley JH, et al., PD-1 blockade induces responses by inhibiting adaptive immune resistance, Nature, 2014;515:568-71

7. Greenberg PD, Adoptive T cell therapy of tumors: mechanisms operative in the recognition and elimination of tumor cells, Adv Immunol, 1991:49:281-355.

8. Cheever MA, Chen W, Therapy with cultured T cells: principles revisited, Immunol Rev, 1997;157:177-94.

9. Kalos M, June $\mathrm{CH}$, Adoptive T cell transfer for cancer immunotherapy in the era of synthetic biology, Immunity, 2013;39:49-60

10. Restifo NP, Smyth MJ, Snyder A, Acquired resistance to immunotherapy and future challenges, Nat Rev Cancer , 2016;16:121-6.

11. Shekarian T, Valsesia-Wittmann S, Caux C, Marabelle A, Paradigm shift in oncology: Targeting the immune system rather than cancer cells, Mutagenesis, 2015;30:205-11.

12. Hodi FS, O'Day SJ, McDermott DF, et al., Improved survival with ipilimumab in patients with metastatic melanoma, $N$ Eng/ J Med, 2010;363:711-23.

13. Topalian SL, Hodi FS, Brahmer JR, Safety, activity, and immune correlates of anti-PD-1 antibody in cancer, N Eng/ I Med, 2012;366:2443-54.

14. Powles T, Eder JP, Fine GD, et al., MPDL3280A (anti-PD-L1) treatment leads to clinical activity in metastatic bladder cancer, Nature, 2014;515:558-62

15. Ansell SM, Lesokhin AM, Borrello I, et al., PD-1 blockade with nivolumab in relapsed or refractory Hodgkin's lymphoma, N Engl J Med, 2015;372:311-9.

16. Brahmer J, Reckamp KL, Baas P, et al., Nivolumab versus docetaxel in advanced squamous-cell non-small-cell lung cancer, N Eng/ J Med, 2015;373:123-35.

17. Hamanishi J, Mandai M, Ikeda T, et al., Safety and antitumor activity of anti-PD-1 antibody, nivolumab, in patients with platinum-resistant ovarian cancer, I Clin Oncol, 2015:33:4015-22.

18. Azoury SC, Straughan DM, Shukla V, Immune checkpoint inhibitors for cancer therapy: Clinical efficacy and safety, Curr Cancer Drug Targets, 2015;15:452-62.

19. La-Beck NM, Jean GW, Huynh C, et al., Immune checkpoint inhibitors: New insights and current place in cancer therapy Pharmacotherapy, 2015;35:963-76.

20. Dadu R, Zobniw C, Diab A, Managing adverse events with immune checkpoint agents, Cancer J, 2016;22:121-9.

21. Rosenberg SA, Restifo NP, Adoptive cell transfer as personalized immunotherapy for human cancer, Science, 2015;348:62-8.

22. Rosenberg SA, Spiess P, Lafreniere R, A new approach to the adoptive immunotherapy of cancer with tumor-infiltrating lymphocytes, science, 1986;233:1318-21.

23. Whiteside TL, Jost LM, Herberman RB, Tumor-infiltrating lymphocytes. Potential and limitations to their use for cancer therapy, Crit Rev Oncol Hematol, 1992;12:25-47.

24. Ahmadi M, King JW, Xue SA, et al., CD3 limits the efficacy of TCR gene therapy in vivo, Blood, 2011;118:3528-37.

25. Abate-Daga D, Hanada K Davis $\Perp$, et al, Expression profiling of TCR-engineered T cells demonstrates overexpression of multiple inhibitory receptors in persisting lymphocytes, Blood, 2013;122:1399-410

26. Palmer DC, Guittard GC, Franco Z, et al., Cish actively silences TCR signaling in CD8+ T cells to maintain tumor tolerance, J Exp Med, 2015;212:2095-113.

27. Eshhar Z, Waks T, Gross G, Schindler DG, Specific activation and targeting of cytotoxic lymphocytes through chimeric single chains consisting of antibody-binding domains and the gamma or zeta subunits of the immunoglobulin and T-cell receptors, Proc Natl Acad Sci U S A, 1993;90:720-4.

28. Kershaw MH, Westwood JA, Darcy PK, Gene-engineered T cells for cancer therapy, Nat Rev Cancer, 2013;13:525-41.

29. Frigault MJ, Lee J, Basil MC, et al., Identification of chimeric antigen receptors that mediate constitutive or inducible proliferation of T cells, Cancer Immunol Res, 2015:3:356-67.

30. Long AH, Haso WM, Shern JF, et al., 4-1BB costimulation ameliorates $\mathrm{T}$ cell exhaustion induced by tonic signaling of chimeric antigen receptors, Nat Med, 2015;21:581-90.

31. Kochenderfer JN, Wilson WH, Janik JE, et al., Eradication of $\mathrm{B}$-lineage cells and regression of lymphoma in a patient treated with autologous $\mathrm{T}$ cells genetically engineered to recognize CD19, Blood, 2010;116:4099-102

32. Klebanoff CA, Rosenberg SA, Restifo NP, Prospects for geneengineered T cell immunotherapy for solid cancers, Nat Med, 2016;22:26-36.

33. Rosenberg SA, Yang JC, Sherry RM, et al., Durable complete responses in heavily pretreated patients with metastatic melanoma using T-cell transfer immunotherapy, Clin Cancer Res, 2011;17:4550-7.

34. Junker $\mathrm{N}$, Kvistborg P, Kollgaard $\mathrm{T}$, et al., Tumor associated antigen specific T-cell populations identified in ex vivo expanded TIL cultures, Cell Immunol, 2012:273:1-9.

35. Hadrup S, Donia M, Thor Straten P, Effector CD4 and CD8 T cells and their role in the tumor microenvironment, Cancer Microenviron, 2013;6:123-33.

36. Lu YC, Yao X, Crystal JS, et al., Efficient identification of mutated cancer antigens recognized by $T$ cells associated with durable tumor regressions, Clin Cancer Res, 2014;20:3401-10

37. Morgan RA, Chinnasamy N, Abate-Daga D, Cancer regression and neurological toxicity following anti-MAGE-A3 TCR gene therapy J Immunother, 2013:36:133-51.

38. Linette GP, Stadtmauer EA Maus MV et al Cardiovascular toxicity and titin cross-reactivity of affinity-enhanced T cells in myeloma and melanoma, Blood, 2013;122:863-71.

39. Parkhurst MR, Yang JC, Langan RC, et al., T cells targeting carcinoembryonic antigen can mediate regression of metastatic colorectal cancer but induce severe transient colitis, Mol Ther, 2011;19:620-6.

40. Robbins PF, Morgan RA, Feldman SA, et al., Tumor regression in patients with metastatic synovial cell sarcoma and melanoma using genetically engineered lymphocytes reactive with NYESO-1, J Clin Oncol, 2011;29:917-24.

41. Chodon T, Comin-Anduix B, Chmielowski B, Adoptive transfer of MART-1 T-cell receptor transgenic lymphocytes and dendritic cell vaccination in patients with metastatic melanoma, Clin Cancer Res, 2014:20:2457-65.

42. Kageyama $\mathrm{S}$, Ikeda $\mathrm{H}$, Miyahara $\mathrm{Y}$, et al., Adoptive transfer of MAGE-A4 T-cell receptor gene-transduced lymphocytes in patients with recurrent esophageal cancer, Clin Cancer Res, 2015;21:2268-77.

43. Robbins PF, Kassim SH, Tran TLN, et al., A pilot trial using lymphocytes genetically engineered with an NY-ESO-1-reactive T-cell receptor: Long-term follow-up and correlates with response, Clin Cancer Res, 2015;21:1019-27.

44. Maude SL, Frey N, Shaw PA, et al., Chimeric antigen receptor $T$ cells for sustained remissions in leukemia, N Eng/ J Med, 2014;371:1507-17

45. Turtle CJ, Hanafi LA, Berger C, et al., CD19 CAR-T cells of defined CD4+:CD8+ composition in adult B cell ALL patients, $J$ Clin Invest, 2016;126:2123-38.

46. Kochenderfer JN, Dudley ME, Kassim SH, et al., Chemotherapyrefractory diffuse large B-cell lymphoma and indolent B-cell malignancies can be effectively treated with autologous $\mathrm{T}$ cells expressing an anti-CD19 chimeric antigen receptor, J Clin Oncol, 2015;33:540-9.

47. Brentjens RJ, Riviere I, Park JH, et al., Safety and persistence of adoptively transferred autologous CD19-targeted T cells in patients with relapsed or chemotherapy refractory B-cell leukemias, Blood, 2011;118:4817-28

48. Davila ML, Riviere I, Wang X, Efficacy and toxicity management of 19-28z CAR T cell therapy in B cell acute lymphoblastic leukemia, Sci Transl Med, 2014;6:224ra25.

49. Brudno JN, Kochenderfer JN, Toxicities of chimeric antigen receptor T cells: Recognition and management, Blood, 2016:127:3321-30

50. Morgan RA Yang JC, Kitano $M$, et al., Case report of a serious adverse event following the administration of T cells transduced with a chimeric antigen receptor recognizing ERBB2 MOI Ther 2010:18:843-51.

51. Bonifant $\mathrm{CL}$, Jackson HJ, Brentjens RJ, Curran KJ, Toxicity and management in CAR T-cell therapy, Mol Ther Oncolytics, 2016;3:16011.

52. Fesnak $A D$, June $C H$, Levine $B L$, Engineered $T$ cells: The promise and challenges of cancer immunotherapy, Nat Rev Cancer, 2016;16:566-81.

53. Kadambi A, Mouta Carreira C, Yun CO, et al., Vascular endothelial growth factor (VEGF)-C differentially affects tumor vascular function and leukocyte recruitment, Cancer Res, 2001;61:2404-8.

54. Musha $\mathrm{H}$, Ohtani $\mathrm{H}$, Mizoi T, et al., Selective infiltration of CCR5+CXCR3+ T lymphocytes in human colorectal carcinoma, Int J Cancer, 2005:116:949-56

55. Harlin $\mathrm{H}$, Meng $\mathrm{Y}$, Peterson $\mathrm{AC}$, et al., Chemokine expression in melanoma metastases associated with CD8+ T-cell recruitment, Cancer Res, 2009:69:3077-85.

56. Cairns RA, Harris IS, Mak TW, Regulation of cancer cell metabolism, Nat Rev Cancer, 2011;11:85-95.

57. Feig C, Jones JO, Kraman M, et al., Targeting CXCL12 from FAP-expressing carcinoma-associated fibroblasts synergizes with anti-PD-L1 immunotherapy in pancreatic cancer, Proc Nat Acad Sci U S A, 2013;110:20212-7.

58. Mulligan AM, Raitman I, Feeley L, et al., Tumoral Iymphocytic infiltration and expression of the chemokine CXCL10 in Breast Cancers from the Ontario Familial Breast Cancer Registry, Clin Cancer Res, 2013;19:336-46.

59. Yewdell JW, Bennink JR, Cell biology of antigen processing and presentation to major histocompatibility complex class I molecule-restricted T lymphocytes, Adv Immunol 1992;52:1-123.

60. Restifo NP, Kawakami Y, Marincola F, et al., Molecular mechanisms used by tumors to escape immune recognition: Immunogenetherapy and the cell biology of major histocompatibility complex class I, I Immunother Emphasis
Tumor Immunol, 1993;14:182-90.

61. Pardoll DM, The blockade of immune checkpoints in cance immunotherapy, Nat Rev Cancer, 2012;12:252-64.

62. Zhao Y, Bennett AD, Zheng Z, et al., High-affinity TCRS generated by phage display provide $\mathrm{CD} 4+\mathrm{T}$ cells with the ability to recognize and kill tumor cell lines, I Immunol, 2007;179:5845-54

63. Vigneron N, Stroobant V, Van den Eynde BJ, van der Bruggen P. Database of T cell-defined human tumor antigens: The 2013 P, Database of T cell-defined human
update, Cancer Immun, 2013;13:15

64. Maher J, Brentiens RJ, Gunset G, et al., Human T-lymphocyte cytotoxicity and proliferation directed by a single chimeric TCR[zeta]/CD28 receptor, Nat Biotech, 2002:20:70-5.

65. Moeller M, Haynes NM, Trapani JA, et al., A functional role for $\mathrm{CD} 28$ costimulation in tumor recognition by single-chain receptor-modified T cells, Cancer Gene Ther, 2004;11:371-9.

66. Guest RD, Hawkins RE, Kirillova N, et al., The role of extracellula spacer regions in the optimal design of chimeric immune

receptors: evaluation of four different scFvs and antigens, Jimmunother, 2005:28:203-11.

67. Carpenito C, Milone MC, Hassan R, et al., Control of large, established tumor xenografts with genetically retargeted human T cells containing CD28 and CD137 domains, Proc Nat Acad Sci U S A, 2009:106:3360-5.

68. Zhao Y, Wang QJ, Yang S, et al., A herceptin-based chimeric antigen receptor with modified signaling domains leads to enhanced survival of transduced T lymphocytes and antitumor activity, I Immunol, 2009;183:5563-74.

69. Bridgeman JS, Hawkins RE, Hombach AA, et al., Building better chimeric antigen receptors for adoptive T cell therapy, Curr Gene Ther, 2010;10:77-90.

70. Zhong XS, Matsushita M, Plotkin J, et al., Chimeric antigen receptors combining 4-1BB and $\mathrm{CD} 28$ signaling domains augment PI3Kinase/AKT/BCl-XL activation and CD8+ T Celmediated tumor eradication, MOl Ther 2010:18:413-20

71. Cheadle EJ, Sheard V, Hombach AA, et al., Chimeric antigen receptors for T-cell based therapy, Methods Mol Biol, 2012;907:645-66

72. Duong CP, Westwood JA, Yong CS, et al., Engineering T cell function using chimeric antigen receptors identified using a DNA library approach, PLOS One, 2013;8:e63037.

73. Kunii $\mathrm{N}$, Zhao Y, Jiang $\mathrm{S}$, et al., Enhanced function of redirected human $\mathrm{T}$ cells expressing linker for activation of $\mathrm{T}$ cells that is resistant to ubiquitylation, Hum Gene Ther, 2013;24:27-37.

74. Kobold S, Grassmann S, Chaloupka M, et al., Impact of a new fusion receptor on PD-1-mediated immunosuppression in adoptive T cell therapy, I Natl Cancer Inst, 2015;107:pii:djv 146.

75. Johnson LA, June CH, Driving gene-engineered T cell immunotherapy of cancer, Cell Res, 2017;27:38-58.

76. Yong CSM, Dardalhon V, Devaud C, et al., CAR T-cell therapy of solid tumors, Immunol Cell Biol, 2017:95:356-63.

77. Slaney CY, Kershaw MH, Darcy PK, Trafficking of T cells into tumors, Cancer Res, 2014:74:7168-74.

78. Kmiecik J, Poli A, Brons NH, et al., Elevated CD3+ and CD8+ tumor-infiltrating immune cells correlate with prolonged survival in glioblastoma patients despite integrated immunosuppressive mechanisms in the tumor microenvironment and at the systemic level, J Neuroimmunol, 2013;264:71-83

79. Galon J, Costes A, Sanchez-Cabo F, et al., Type, density, and location of immune cells within human colorectal tumors predict clinical outcome, Science, 2006;313:1960-4.

80. Kim ST, Jeong $\mathrm{H}$, Woo OH, et al., Tumor-infiltrating lymphocytes, tumor characteristics, and recurrence in patients with early breast cancer, Am J Clin Oncol, 2013;36:224-31.

81. Piersma SJ, Jordanova ES, van Poelgeest MI, et al. High number of intraepithelial CD8+ tumor-infiltrating lymphocytes is associated with the absence of lymph node metastases in patients with large early-stage cervical cancer, Cancer Res, 2007;67:354-61.

82. Galon J, Mlecnik B, Bindea G, et al., Towards the introduction of the 'Immunoscore' in the classification of malignant tumours, I Pathol, 2014;232:199-209.

83. von Andrian UH, Chambers JD, MCEvoy LM, et al., Two-step model of leukocyte-endothelial cell interaction in inflammation: Distinct roles for LECAM-1 and the leukocyte beta 2 integrins in vivo, Proc Natl Acad Sci U S A, 1991;88:7538-42.

84. von Andrian UH, Hansell P, Chambers JD, et al., L-selectin function is required for beta 2-integrin-mediated neutrophil adhesion at physiological shear rates in vivo, Am J Physiol, 1992;263: H1034-44.

85. Gallatin WM, Weissman IL, Butcher EC, A cell-surface molecule involved in organ-specific homing of lymphocytes, Nature, 1983:304:30-4.

86. Bargatze $\mathrm{RF}$, Butcher $\mathrm{EC}$, Rapid $\mathrm{G}$ protein-regulated activation event involved in lymphocyte binding to high endothelia venules, J Exp Med, 1993;178:367-72.

87. Campbell JJ, Hedrick J, Zlotnik A, et al., Chemokines and the arrest of lymphocytes rolling under flow conditions, Science, 1998;279:381-4

88. von Andrian $\mathrm{UH}$, Mackay $\mathrm{CR}$, T-cell function and migration. Two sides of the same coin, N Eng/ J Med, 2000;343:1020-34.

89. Ley K, Laudanna C, Cybulsky MI, Nourshargh S, Getting to the site of inflammation: The leukocyte adhesion cascade updated Nat Rev Immunol, 2007:7:678-89.

90. Godfrey DI, Zlotnik A, Control points in early T-cell development, Immunol Today, 1993;14:547-53.

91. Berger EA, HIV entry and tropism: the chemokine receptor connection, Aids, 1997;11:S3-16.

92. Luster $A D$, Chemokines-chemotactic cytokines that mediate inflammation, N Eng/ J Med, 1998;338:436-45

93. Kim $\mathrm{CH}$, Broxmeyer $\mathrm{HE}$, Chemokines: Signal lamps for trafficking of $T$ and $B$ cells for development and effecto 
sensitivity, Nature, 2012;483:603-7.

101. Atretkhany KSN, Drutskaya MS, Nedospasov SA, et al , Chemokines, cytokines and exosomes help tumors to shape inflammatory microenvironment, Pharmacol Ther, 2016:168:98-112.

102. Curiel TJ, Coukos G, Zou L, et al., Specific recruitment of regulatory $\mathrm{T}$ cells in ovarian carcinoma fosters immune privilege and predicts reduced survival, Nat Med, 2004;10:942-9.

103. Facciabene A, Peng $X$, Hagemann IS, et al., Tumour hypoxia promotes tolerance and angiogenesis via CCL28 and T(reg) cells, Nature, 2011;475:226-30.

104. Rapp M, Grassmann S, Chaloupka M, et al., C-C chemokine receptor type-4 transduction of $\mathrm{T}$ cells enhances interaction with dendritic cells, tumor infiltration and therapeutic efficacy of adoptive T cell transfer, Oncoimmunology, 2016;5:e1105428.

105. Bailey C, Negus R, Morris A, et al., Chemokine expression is associated with the accumulation of tumour associated macrophages (TAMS) and progression in human colorectal macrophages (TAMs) and progression in hum

106. Hong M, PuauX AL, Huang C, et al., Chemotherapy induces intratumoral expression of chemokines in cutaneous melanoma, favoring T-cell infiltration and tumor control, Cancer Res, 2011;71:6997-7009

107. Baj-Krzyworzeka M, Weglarczyk K, Mytar B, et al., Tumourderived microvesicles contain interleukin- 8 and modulate production of chemokines by human monocytes, Anticance Res, 2011;31:1329-35.

108. Mantovani A, Sica A, Sozzani S, et al., The chemokine system in diverse forms of macrophage activation and polarization, Trends Immunol, 2004:25:677-86.

109. Qian BZ, Pollard JW, Macrophage diversity enhances tumor progression and metastasis, Cell, 2010;141:39-51.

110. Aldinucci D, Colombatti A, The inflammatory chemokine CCL5 and cancer progression, Mediators Inflamm CCL5 and cancer p

111. Vaday GG, Peehl DM, Kadam PA, Lawrence DM, Expression of CCL5 (RANTES) and CCR5 in prostate cancer, Prostate, 2006;66:124-34

112. Kitamura T, Kometani K, Hashida H, et al., SMAD4-deficient intestinal tumors recruit CCR1+ myeloid cells that promote invasion, Nat Genet, 2007;39:467-75.

113. Chow MT, Luster AD, Chemokines in cancer, Cancer Immuno Res, 2014;2:1125-31.

114. Das S, Sarrou E, Podgrabinska S, et al., Tumor cell entry into the lymph node is controlled by CCL1 chemokine expressed by Iymph node lymphatic sinuses, J Exp Med, 2013;210:1509-28.

115. Strieter RM, Burdick MD, Gomperts BN, et al., CXC chemokines in angiogenesis, Cytokine Growth Factor Rev, 2005;16:593-609. 16. Nagasawa T, Hirota S, Tachibana K, et al., Defects of B-cell lymphopoiesis and bone-marrow myelopoiesis in mice lacking lymphopoiesis and bone-marrow myelopoiesis in mice lack

117. Tachibana $K$, Hirota S, lizasa $H$, et al., The chemokine recepto CXCR4 is essential for vascularization of the gastrointestinal tract, Nature, 1998;393:591-4.

118. Devaud C, John LB, Westwood JA, et al., Immune modulation of the tumor microenvironment for enhancing cancer immunotherapy, Oncoimmunology, 2013;2:e25961.

119. Roselli M, Cereda V, di Bari MG, et al., Effects of conventional therapeutic interventions on the number and function of regulatory T cells, Oncoimmunology, 2013;2:e27025.

120. Oelkrug C, Ramage JM, Enhancement of T cell recruitment and infiltration into tumours, Clin Exp Immunol, 2014;178:1-8.

121. Clark-Lewis I, Schumacher C, Baggiolini M, Moser B, Structure-activity relationships of interleukin-8 determined using chemically synthesized analogs. Critical role of $\mathrm{NH}_{2}-$ terminal residues and evidence for uncoupling of neutrophil terminal residues and evidence for uncoupling of neutrophil chemotaxis, exocytosis, and
Chem, 1991;266:23128-34.

122. Zhang $Y$, Rollins $B J$, A dominant negative inhibitor indicates that monocyte chemoattractant protein 1 functions as a dime Mol Cell Biol, 1995;5:4851-5.

123. Gong JH, Uguccioni M, Dewald B, et al., RANTES and MCP-3 antagonists bind multiple chemokine receptors, J Biol Chem, 1996:271:10521-7.

124. Koga M, Kai H, Egami K, et al., Mutant MCP-1 therapy inhibits tumor angiogenesis and growth of malignant melanoma in mice, Biochem Biophys Res Commun, 2008:365:279-84.

125. Klarenbeek A, Maussang D, Blanchetot $C$, et al., Targeting chemokines and chemokine receptors with antibodies, Drug Discov Today, 2012;9:e237-44.

126. Proudfoot AEI, Bonvin P, Power CA, Targeting chemokines: Pathogens can, why can't we?, Cytokine, 2015;74:259-67.

127. Peng W, Liu C, Xu C, et al., PD-1 blockade enhances T-cel migration to tumors by elevating IFN-gamma inducible chemokines, Cancer Res, 2012;72:5209-18.

128. Fluhr H, Seitz T, Zygmunt M, Heparins modulate the IFNgamma-induced production of chemokines in human breast cancer cells, Breast Cancer Res Treat, 2013;137:109-18.

129. Hoelzinger DB, Smith SE, Mirza N, et al. Blockade of CCL1 inhibits T regulatory cell suppressive function enhancing tumo immunity without affecting T effector responses, I Immuno 6833-42.

130. Spear P, Barber A, Sentman CL, Collaboration of chimeric antigen receptor (CAR)-expressing T cells and host T cells for optimal elimination of established ovarian tumors, Oncoimmunology, 2013;2: e23564.

131. Guirnalda P, Wood L, Goenka R, et al., Interferon gammainduced intratumoral expression of CXCL9 alters the local distribution of T cells following immunotherapy with Listeria monocytogenes, Oncoimmunology, 2013;2:e25752.

132. Tannenbaum $C S$, Tubbs $R$, Armstrong $D$, et al., The CXC chemokines IP-10 and Mig are necessary for IL-12-mediated regression of the mouse RENCA tumor, I Immunol, 1998;161:927-32.

133. lezzi G, Karjalainen K, Lanzavecchia A, The duration of antigenic stimulation determines the fate of naive and effector $T$ cells, Immunity, 1998;8:89-95.

134. Hou S, Hyland L, Ryan KW, et al., Virus-specific CD8 T-cell memory determined by clonal burst size, Nature 1994;369:652-4.

135. Busch DH, Pilip IM, Vijh S, Pamer EG, Coordinate regulation of complex T cell populations responding to bacterial infection, Immunity, 1998;8:353-62

136. Bachmann MF, Barner M, Viola A, Kopf M, Distinct kinetics of cytokine production and cytolysis in effector and memory cells after viral infection, Eur J Immunol, 1999;29:291-9.

137. Veiga-Fernandes $\mathrm{H}$, Walter $\mathrm{U}$, Bourgeois $\mathrm{C}$, et al., Response of naive and memory $\mathrm{CD} 8+\mathrm{T}$ cells to antigen stimulation in vivo Nat Immunol, 2000;1:47-53.

138. Sallusto F, Lenig D, Forster R, et al., Two subsets of memory T lymphocytes with distinct homing potentials and effector Tlymphocytes with distinct homing
functions, Nature, 1999:401:708-12.

139. Johansson-Lindbom B, Svensson M, Wurbel MA et al., Selective generation of gut tropic T cells in gut-associated lymphoid tissue (GALT): Requirement for GALT dendritic cells and adjuvant, J Exp Med, 2003;198:963-9.

140. Mora JR, Bono MR, Manjunath N, et al., Selective imprinting of gut-homing T cells by Peyer's patch dendritic cells, Nature, 2003;424:88-93

141. Dudda JC, Simon JC, Martin S, Dendritic cell immunization route determines $C D 8+T$ cell trafficking to inflamed skin: Role for tissue microenvironment and dendritic cells in establishment of T cell-homing subsets, J Immunol, 2004;172:857-63.

142. Mora JR, Cheng G, Picarella D, et al., Reciprocal and dynamic control of CD8 T cell homing by dendritic cells from skin- and gut-associated lymphoid tissues, J Exp Med, 2005;201:303-16.

143. Ferguson AR, Engelhard VH, CD8 T cells activated in distinct lymphoid organs differentially express adhesion proteins and coexpress multiple chemokine receptors, I Immuno and coexpress mu

144. Kershaw $M H$, Wang $G$, Westwood, et al., Redirecting migration of T cells to chemokine secreted from tumors by genetic modification with CXCR2, Hum Gene Ther, 2002;13:1971-80.

145. Idorn M, Thor Straten P, Svane IM, Met O, Transfection of tumo infiltrating T cells with mRNA encoding CXCR2, Methods Mol
Biol, 2016;1428:261-76

146. Di Stasi A, De Angelis B, Rooney CM, et al., T lymphocytes coexpressing CCR4 and a chimeric antigen receptor targeting CD30 have improved homing and antitumor activity in Hodgkin tumor model, 2009:113:6392-402.

147. Craddock JA, Lu A, Bear A, et al., Enhanced tumor trafficking of $\mathrm{GD} 2$ chimeric antigen receptor T cells by expression of the chemokine receptor CCR2b, I Immunother, 2010;33:780-8.

148. Moon EK, Carpenito C, Sun J, et al., Expression of a functiona CCR2 receptor enhances tumor localization and tumor eradication by retargeted human $\mathrm{T}$ cells expressing a mesothelin-specific chimeric antibody receptor, Clin Cancer Res, 2011;17:4719-30.

149. Siddiqui I, Erreni $M$, van Brakel M, et al., Enhanced recruitment of genetically modified CX3CR1-positive human T cells into Fractalkine/CX3CL1 expressing tumors: Importance of the chemokine gradient, I Immunother Cancer, 2016:4:21.

150. Carlsten M, Levy E, Karambelkar A, et al., Efficient mRNA-based genetic engineering of human NK cells with high-affinity CD16 and CCR7 augments rituximab-induced ADCC against lymphoma and targets NK cell migration toward the lymph node-associated chemokine CCL19, Front Immunol, 2016;7:105

151. Xu Y, Hyun YM, Lim K, et al., Optogenetic control of chemokine receptor signal and T-cell migration, Proc Natl Acad Sci U S A, 2014;111:6371-6.

152. Soriano JL, Batista N, Santiesteban E, et al., Metronomic cyclophosphamide and methotrexate chemotherapy combined with 1 E10 anti-idiotype vaccine in metastatic breast cancer, Int J Breast Cancer, 2011;2011:710292.

153. Hu J, Zhu S, Xia X, et al., CD8+T cell-specific induction of NKG2D receptor by doxorubicin plus interleukin-12 and its contribution to CD8+T cell accumulation in tumors, Mol Cancer, 2014;13:34.

154. Chinnasamy D, Yu Z, Kerkar SP, et al., Local delivery of interleukin-12 using T cells targeting VEGF receptor-2 interleukin-12 using T cells targeting VEGF receptor-2 Res, 2012:18:1672-83.

155. DirkX AE, Oude Egbrink MG, Kuijpers MJ, et al., Tumor angiogenesis modulates leukocyte-vessel wall interactions in vivo by reducing endothelial adhesion molecule expression, Cancer Res, 2003;63:2322-9.

156. Shrimali RK, Yu Z, Theoret MR, et al., Antiangiogenic agents can increase lymphocyte infiltration into tumor and enhance the effectiveness of adoptive immunotherapy of cancer, Cancer Res, 2010;70:6171-80.

157. DirkX AE, Oude Egbrink MG, Castermans K, et al., Antiangiogenesis therapy can overcome endothelial cell anergy and promote leukocyte-endothelium interactions and infiltration in tumors, FASEB J, 2006:20:621-30.

158. Ganss R, Ryschich E, Klar E, et al., Combination of T-cell therapy and trigger of inflammation induces remodeling of the vasculature and tumor eradication, Cancer Res, 2002:62:1462-70

159. Buckanovich RJ, Facciabene A, Kim S, et al., Endothelin B receptor mediates the endothelial barrier to $\mathrm{T}$ cell homing to tumors and disables immune therapy, Nat Med, 2008;14:28-36.

160. Legler DF, Johnson-Leger C, Wiedle G, et al., The alpha v beta 3 integrin as a tumor homing ligand for lymphocytes, Eur J Immunol, 2004;34:1608-16.

161. Wu L, Yun Z, Tagawa T, et al., CTLA-4 blockade expands infiltrating T cells and inhibits cancer cell repopulation during the intervals of chemotherapy in murine mesothelioma Mol Cancer Ther, 2012;11:1809-19.

162. Kobold S, Steffen J, Chaloupka M, et al., Selective bispecific T cell recruiting antibody and antitumor activity of adoptive $T$ cel transfer, I Natl Cancer Inst, 2015;107:364.

163. Parente-Pereira AC, Burnet J, Ellison D, et al. Trafficking of CAR-engineered human T cells following regional or systemic adoptive transfer in SCID beige mice, J Clin Immunol, 2011;31:710-8.

164. Adusumilli PS, Cherkassky L, Villena-Vargas J, et al., Regional delivery of mesothelin-targeted CAR T cell therapy generates potent and long-lasting CD4-dependent tumor immunity, SC Trans/ Med, 2014;6:261ra151. 